\title{
Potential Natural Aromatase Blockers on Enhance the Frequency and Sound Quality of Male Canaries
}

\author{
Pudji Astuti ${ }^{1, *}$, Claude M. Airin ${ }^{1}$, Alfarisa Nurrurozi $^{1}$, Rizal Aidi $^{2}$, Amelia Hana $^{1}$, Susilo Hadi ${ }^{3}$, and Harimurti \\ Harimurti $^{4}$ \\ ${ }^{1}$ Faculty of Veterinary Medicine, Universitas Gadjah Mada Yogyakarta, Indonesia \\ ${ }^{2}$ Postgraduate student, Faculty of Veterinary Medicine, Universitas Gadjah Mada Yogyakarta, Indonesia \\ ${ }^{3}$ Faculty of Biology Universitas Gadjah Mada Yogyakarta, Indonesia \\ ${ }^{4}$ Faculty of Animal Science, Universitas Gadjah Mada Yogyakarta, Indonesia
}

\begin{abstract}
The quality sound of singing birds strongly depends on testosterone. Unfortunately, most of the testosterone will be converted to estradiol by the aromatase enzyme. The study aimed to examine the potential of natural aromatase blockers for increasing the frequency and quality of canary chirps. Five adult male canaries, with bodyweight 25-30 g were used in the study. After being adapted for a week, birds were fed a mixture of aromatase blockers and canary seed for 20 days at a dose of $0.3 \mathrm{mg} / 30 \mathrm{~g}$ body weight. Quantities of a song using Hagemon touch methods were calculated by frequency of chirping for 10 minutes, whereas the quality of the song was counted by the periods of once chirping for 10 minutes. Recording begins when the bird is given standard feeding and repeated after treatment for 20 days. The results showed that the frequency of chirping before given a mixture of ingredients was $15.3 / 10$ min, after being treated with aromatase blockers the frequency increased up to 78.9/10 min. The length of the tweet before treatment was $<1 \mathrm{~s}$ while after treatment up to $17 \mathrm{~s}$. It can be concluded that aromatase blockers can increase the frequency and quality of male Canary's song.
\end{abstract}

Keywords: canary, hegemon touch, frequency of sound, quality, aromatase blocker.

\section{Introduction}

The fans of singing birds in Indonesia are increasing every day. In order to enhance the quality and quantity of singing birds' voices, testosterone hormone was injected directly. However, the use of testosterone hormone causing feather loss, sound loss even death. Thus, solutions to increase the quality and quantity of the singing birds' voices without giving dangerous side effects were needed.

It is known that the voice of singing birds was controlled by testosterone. But inside the body, testosterone will transfer into estrogen by aromatase enzyme that makes the testosterone level can't be maintained. Astuti et al [1], has reported that in rats, giving the natural aromatase blocker will increase the testosterone level in the blood, relieve the expression of Cyp19 aromatase both in the brain or Leydig cell. It means the natural aromatase blockers that given can maintain the testosterone level in the blood so the frequency of singing birds tweeting will increase. Based on this research aromatase natural blockers are assumed to work in canary. The study aimed to investigate the potential of aromatase natural blocker towards the quantity and quality of male canary birds' voices. The overuse of aromatase blockers, the body could select the needs of testosterone, so there will be no excess of testosterone productions'. Thus, the loss of feather and incoordination movement, even death can be prevented.

If the study works smoothly, it is hoped that there will be a super feed special for singing birds without giving any dangerous side effects.

\section{Materials and methods}

Five male adult canaries, weigh 25-30 grams obtained from canary breeders in Yogyakarta, were used in this study. The virility of the birds characterized by brownish color on Os Humerus. All animals are adapted for 1 week.

Before being treated, the vice recording of the birds was done using the Hagemon Touch Method. The recording was carried out around $07.00 \mathrm{am}-08.00 \mathrm{am}$ for 10 minutes. Furthermore, four birds were given standard feed and natural aromatase blockers at a dose of $0.3 \mathrm{mg}$ per 30 gram of body weight, the latest one was used as a control that given the standard canary feed ad libitum. The aromatase blockers were given for 20 days, based on the spermatogenesis period of poultry.

The sound quantity test is based on the number of votes every 10 minutes, while the sound quality is done by looking at the length of the chirp. All the research procedures have been approved by the Integrated

*Corresponding author: pastuti2@ugm.ac.id 
Research and Testing Laboratory (LPPT-UGM) Ethics committee with the number of 00021/04 / LPPT / V / 2019. Sound quality grouping is categorized into 4 groups: simple calling $(\leq 1 \mathrm{~s})$; Half calling (1-5s); Full calling (6-10s); continuous calling ( $\geq 10 \mathrm{~s})$.

\section{Results and discussion}

The chirp of the male birds is controlled by testosterone produced in both Leydig cells and the brain [2]. The vocalization of these birds involves the regulation of respiration, especially when air passes through the stretches of the syrinx membrane. The structure of the syrinx cartilage plays an important role in the separation of sound frequencies and amplitude control, which enables new explanations about the successful evolution of songbirds [3]. Former researchers stated that smooth muscle cells reaching from the lateral parts of the interbronchial ligament to the medial line and cranially to the inner tympani form membranes were demonstrated. It would be supposed that these muscle cells play a role in syringeal sound generation by influencing the tension of the medial tympaniform membranes [4].

A series of brain centers serving to control the output of the tracheosyringeal division of the hypoglossal motor nucleus that innervates syringeal muscles.

In this study, calling is grouped into 4 groups: simple calling ( $\leq 1 \mathrm{~s})$; half calling (1-5s); full calling (6-10s); continuous calling $(\geq 10 \mathrm{~s})$. For the control group, some birds only had a simple calling as shown in Figure 1. Furthermore, the period after the administration of natural aromatase blockers was marked by the absence of chirping. However, 3-7 days later the birds returned to chirping even with very high quality, mad grouped from half-calling to continuing calling (Figure 2).

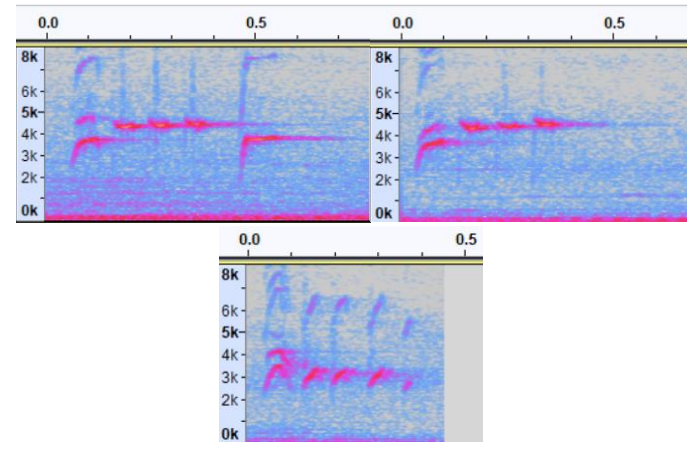

Figure 1. Average of simple calling on the animal before administration of natural aromatase blockers.

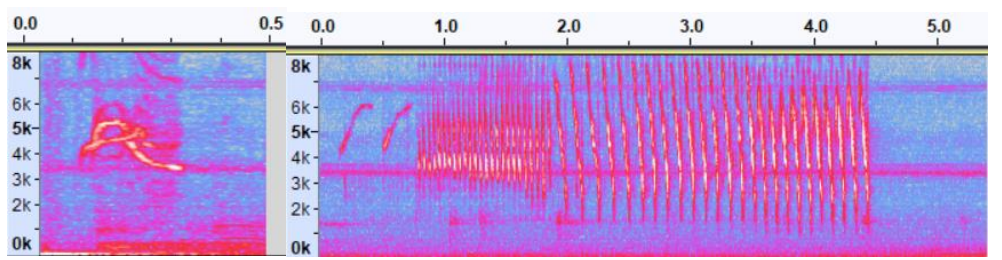

A

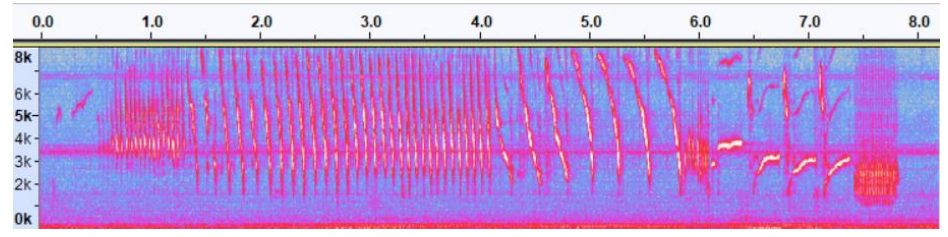

B

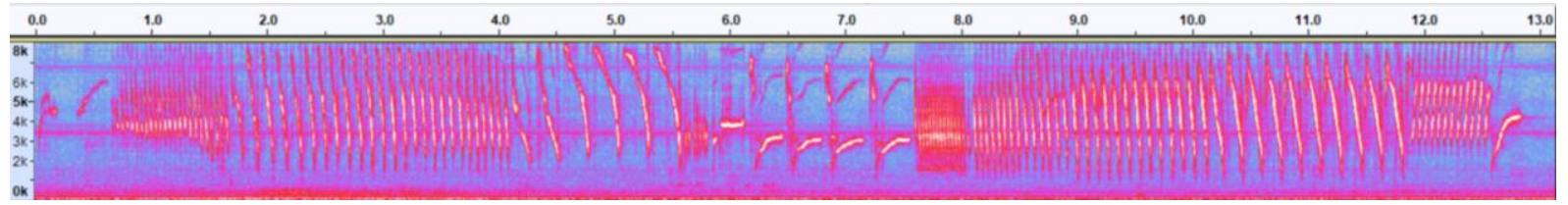

Figure 2. Simple calling $(\leq 1 \mathrm{~s})$ which was shown on the left side of A, whereas Half Calling $(1-5 \mathrm{~s})$ was shown on the right side of A. Figure B was shown as Full calling with (6-10s) of chirping, whereas $\mathrm{C}$ was of continues calling $(\geq 10 \mathrm{~s})$.

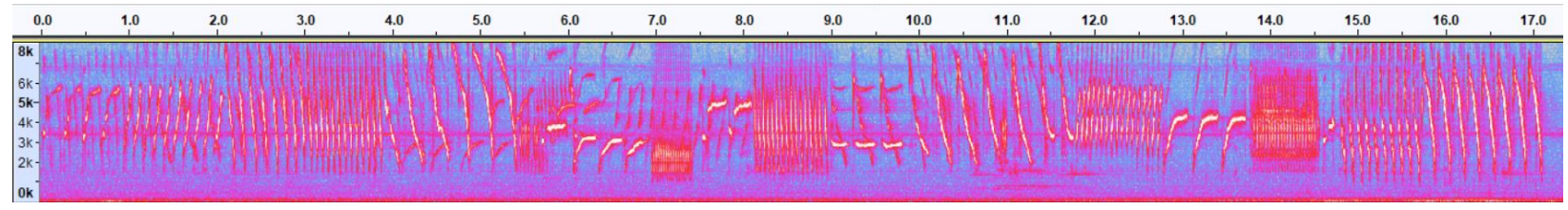

Figure 4. The longest chirping of canary after administration of natural aromatase blockers, the longest periods was 17 seconds. 
The results showed simple calling $(\leq 1 \mathrm{~s})$ as much as $45 \%$, Half calling (1-5s): $23 \%$; Full calling (6-10s): $20 \%$; continuous calling $(\geq 10 \mathrm{~s}): 12 \%$ (Figure 3 ). From the results, the longest sound was obtained in 2 birds with a chirping duration of 17 seconds (Figure 4).

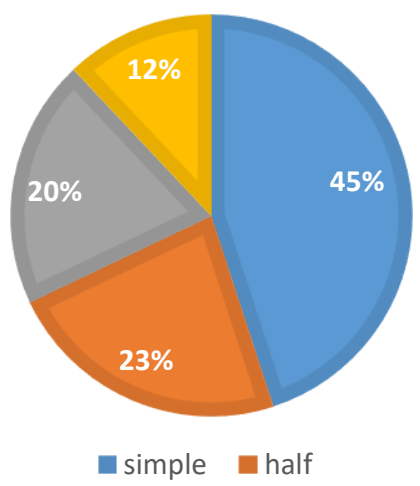

Figure 3. Percentage of bird song after administration of natural aromatase blockers namely simple calling $(\leq 1 \mathrm{~s}): 45 \%$, Half calling (1-5s): $23 \%$; Full calling (6-10s): $20 \%$; continues calling ( $\geq 10 \mathrm{~s}): 12 \%$.

In many cases, the size of the syrinx and the diameter of the latitude muscles correlated with body size. Content of superfast fibers in the syrinx does not appear to be correlated with singing ability, because non-singing females do not consistently show lower superfast fiber content. Instead, the percentage of superfast fibers in syringeal muscles may be connected to the involvement of neuromuscular control in the generation of the acoustic structure and the entire vocal repertoire of a species [5].

Different from aromatase blockers, testosterone blockers do not have exactly opposite effects, often decreasing song but with minor-to-no effects on malemale aggression $[6,7,8]$. Previous researcher stated that testosterone blockers affected aggression but not song, contrasting with results from previously published testosterone implant studies. Effects on paternal care were concordant with testosterone implant studies. It was indicated that several arctic passerines are behaviorally insensitive to testosterone [9].

\section{Conclusion}

It can be concluded that aromatase blockers can increase the frequency and quality of male Canary's song.

\section{References}

1. Astuti Pudji. Claude Mona Airin, Alfarisa Nururrozi, et al:: Oyster Shell Powder as Alternatives Macromineral for Synthetic Testosterone. Proceedings of the 20th FAVA \& the 15th KIVNAS PDHI 2018. November 1-3, 2018. Nusa Dua Convention Centre, Bali - Indonesia.

2. Alward, Charlotte A. Cornil Jacques Balthazart. et al.: The regulation of birdsong by testosterone: Multiple time-scales and multiple sites of action. Hormones and Behavior. 2018;(104):32-40. https://doi.org/10.1016/j.yhbeh.2018.04.010.

3. Düring DN, Alexander Ziegler, Christopher K Thompson, et al.: The Songbird Syrinx Morphome: a three-dimensional, high-resolution, interactive morphological map of the zebra finch vocal organ. BMC Biol. 2013;11(1):1-27. Doi: 10.1186/17417007-11-1.

4. Frank T, Walter I, Probst A, et al.: Histological aspects of the syrinx of the male mallard (Anas platyrhynchos). Anat Histol Embryol. 2006;35(6):396-401.

5. Christensen LA, Lisa M. Allred, Franz Goller, et al.: Is sexual dimorphism in singing behavior related to syringeal muscle composition? The AUK. 2017. (134):pp.710-720 DOI: 10.1642/AUK-17-3.1.

6. Beau A. Alward, Jacques Balthazart, Gregory F. Ball. Dissociable Effects on Birdsong of Androgen Signaling in Cortex-Like Brain Regions of Canaries. The Journal of Neuroscience. 2017;37(36):8612-8624.

7. Beau A. Alward, Catherine de Bournonville, Trevor T. Chan, et al:: Aromatase inhibition rapidly affects in a reversible manner distinct features of birdsong. Scientific Reports.2016;6:3234. DOI: 10.1038/srep32344, www.nature.com/scientificreports/.

8. Rosenfeld CS, Shay DA, Victoria J, et al: Cognitive Effects of Aromatase and Possible Role in Memory Disorders. Front. Endocrinol.2018;9(610):1-14 https://doi.org/10.3389/fendo.2018.00610.

9. Hunt KE, Hahn TP, Buck CL, et al.: Effect of testosterone blockers on male aggression, song and parental care in an arctic passerine, the Lapland longspur (Calcarius lapponicus). Horm Behav. 2019;110:10-18. doi: 10.1016/j.yhbeh.2019.02.001. 